\title{
Ipar Euskal Herria eta ikus-entzunezkoak: Harreman emankor eta herren baten kartografia
}

\author{
Iparralde y el audiovisual: Cartografía \\ de una próspera y asimétrica relación
}

\section{The Northern Basque Country and audiovisual: Cartography of a profitable and asymmetrical connection}

Josu Martinez'

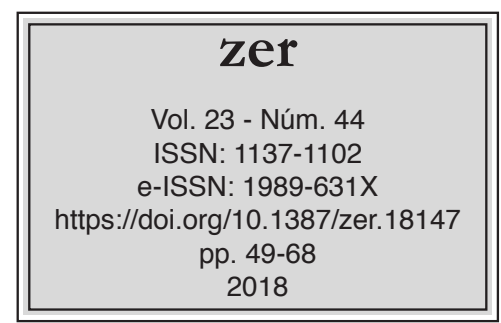

Recibido el 17 de octubre de 2017, aceptado el 13 de febrero de 2018.

\section{Laburpena}

Artikulu honek, Ipar Euskal Herriak eta bertako euskaldunek ikus-entzunezkoekin (zinemarekin, telebistarekin eta bideogintzarekin) izandako harremana aztertzen du, ikuspegi historiko batetik. Ikus-entzunezkoen historian ekarpen nabarmenak egin, euskal ikus-entzunezkogintzan hainbat aldiz aitzindari jokatu duen lurraldea izanagatik, nekeza izan da orain arte bertoko filmagintza bat garatu ahal izatea. Ondoko lerroetan, zinemaren hasmentatik gaurdaino, ikus-entzunezkoetan nabarmendutako Iparraldeko euskaldunak izango ditugu lehenik aipagai; segidan, Ipar Euskal Herriaz egindako frantses eta atzerritar film ospetsuenak aztertu, eta bukatzeko, Iparraldeko euskaldunek sortutako ekoizpenen historia deskriptiboa egingo dugu. Hala, orain arte apenas tratatua izan den gai batenganako lehen hurbilketa burutuko dugu.

Gako-hitzak: ikus-entzunezkoa; kultura; hizkuntza; historia; Euskal Herria; Frantzia.

\section{Resumen}

Este artículo analiza la relación entre el Audiovisual y los vascos del norte. A pesar de ser Iparralde un territorio que ha hecho aportes relevantes en la historia del Audiovisual vasco, hasta hoy no se han dado condiciones para desarrollar una filmografía normalizada. En estas lineas, estudiaremos primero la historia de los realizadores vasco-continentales "exiliados"

\footnotetext{
Universidad del País Vasco/Euskal Herriko Unibertsitatea, josu.martinez@ehu.eus
} 
del país, seguidamente analizaremos las obras realizadas por extranjeros en Iparralde y finalmente, esbozaremos una historia de la producción vasca. Tratándose de un tema apenas estudiado, este trabajo pretende ser una primera aproximación histórica, cartografía de una relación tan fructifera como asimétrica.

Palabras clave: audiovisual; cultura; lenguas minoritarias; historia; País Vasco; Francia.

\begin{abstract}
This article studies the connection of the Northern Basque Country with audiovisual, from a historical viewpoint. Although it has been a region that has contributed a lot to basque audiovisual history, Iparralde has had, up to now, a difficult time in developing it. In the following lines, we will first study the well-known basque filmmakers from Iparralde; then, we will analyse the french and foreign films produced about the Northern Basque Country, and as a conclusion, we will make the history of the films created by the basques in Iparralde. Thus, we will carry out a first approach to the subject of an art that has not been much worked on.
\end{abstract}

Keywords: audiovisual; culture; minority languages; history; Basque Country; France. 


\section{Sarrera}

Ikus-entzunezkoak eta Ipar Euskal Herria. Ipar Euskal Herria eta ikus-entzunezkoak. Hara hor, zinemaren lehen urteetatik bertatik planteatu den ekuazio bateko bi aldagaiak. Ehun urtean, harreman etengabe eta emankorrean bizi izan dira biak, baina orobat, harreman herren eta zentzu bakarrekoan. Grafikoki esateko: usu, jori eta kondizio profesionaletan izan da "Ikus-entzunezkoetan Ipar Euskal Herria", baina aldi berean, nekez, urri, eta maila artisanalean garatu dira "Ipar Euskal Herrian ikus-entzunezkoak". Leku guti dira munduan, hain txikiak izanik, hainbeste aldiz filmatuak izan, hainbeste egile ospetsu erakarri, eta hainbeste izar esportatu dutenak. Aldiz, guzti honek ez dio deus handirik ekarri euskaldungoaren komunitateari. Ez du zerbitu bertako filmagintza bat garatzeko, ez eta euskaldunentzako filmak ekoizteko baldintzak ezartzeko.

Bitxi da bitxi, gaiari buruz dagoen hutsune epistemologikoa. Frantziar estatuko beste nazio batzuetan bertako zinemagintzaren inguruko monografia sendoak dauden bitartean (Mattei, 2008; Gozillon-Fronsacq, 2003) Ipar Euskal Herriakoaz apenas idatzi den deus. Publikatutakoaren artean, Iparraldea eta bertako euskaldunak zeharka aintzat hartuak izan dira (Hego) Euskal Herriko zinemagintzari buruzko zenbait obretan (Zunzunegui, 1985; Unsain, 1985; Roldan Larreta, 2003). Eta bestetik, autore edo esperientzia filmiko zehatzen inguruko lan berezitu batzuek ere ikusi dute argia (Arbelbide, 2002; Martinez, 2014; 2016). Hortik goiti, gaia saihetsetik hartzen duen artikulu bakanen bat salbu (Cheval, 2005), basamortua erabatekoa da.

Artikulu honetan, "Iparraldea eta ikus-entzunezkoak" harremanak ekoizpen mailan emandakoaren ikuspegi orokorra ematen saiatuko gara, deskriptiboki eta enfoke historiko batetik. Zineman eta telebistan nabarmendutako Iparraldeko euskaldunak izango ditugu lehenik aipagai; segidan, Ipar Euskal Herriaz egindako frantses eta atzerritar film ospetsuenak gogoan hartu, eta bukatzeko, Iparraldeko euskaldunek sortutako ekoizpenen historia egingo dugu.

\section{Metodologia}

Ikerlana burutzeko, metodologia kualitatiboa erabili dugu: batik-bat, iturri dokumentalen berrirakurketa kritikoa, eta zenbait eragilerekin egindako elkarrizketa pertsonalak. Horiei esker orain arte plazaratu gabeko zenbait datu ere, ekartzen ditu artikulu honek argitara, lehen aldiz.

Analisi historikoaren eta kulturaren soziologiaren ikuspegitik, egileak eta filmak haien kontestu sozialean aztertu ditugu, beren egitasmoen motibazioei, edukiei, eta haien lanek izandako oihartzunei erreparatuz.

Analisi bibliografiko, hemerografiko eta epistolar zabal batean oinarritu dugu gure lanaren lehen parte handia. Horretarako, lehen eta bigarren mailako iturriak

\footnotetext{
2 Oro har, "ikus-entzunezkoak" kontzeptua erabiliko dugu: zinemaz gain, telebistarako edo eta bideo formatuan egindako lanak ere aipatzeko. Hala ere, zenbait aldiz "zinema" edo "zinegile" kontzeptuak izango ditugu ahotan, bereziki, 70eko hamarkadara arte, horixe izan baita ikus-entzunezko medio nagusia. Nolanahi dela, gure aztergaia mugatzeko irizpidea, "film" kontzeptua izan da: filmak aztertuko ditugu, "film" hitzetik ulertuz, fikzio zein ez-fikziozko ikus-entzunezko obra buruhaski bat, intentzio narratibo edo artistiko batek egina dena.
} 
baliatu ditugu. Lehen mailako iturrien artean, Iparraldeko "Gure Herria", "Basqueeclair", "Herria" eta "Elgar" agerkariak kontsultatu ditugu, aurrez ezagututako data seinalatuetan zentratuz, Baionako udal liburutegian egindako egonaldietan. Bestalde, Baionako Euskal Museoaren, Pariseko Cinématheque Française-aren eta Donostiako Euskadiko Filmategiaren funtsak ere aztertu ditugu, bai eta ere, Madré eta Ynchausti familien artxibo pribatuak. Horretaz gain, ahal izan dugun guztietan -ez nahi bestetan, zoritxarrez- aztertutako filmak ikuskatu ditugu, bai arestian aipatu artxibategietan, bai sarean .

Horrekin batera, gure analisiaren bigarren iturri printzipala, hau ere lehen mailakoa, filmegile eta lekukoekin burututako elkarrizketa sakonak izan dira. Hamairu elkarrizketa burutu ditugu guztira, profil ezberdineko informanteekin: Marcel Rekalde (lekuko historikoa), Mikel Ezkerro (historiadorea), Antonio Ynchausti (zinegilea 40-50eko hamarkadetan), Juanmiguel Gutierrez (zinegilea 70-80ko hamarkadetan), Kristiane Etxaluz (zinegile eta herri mugimenduetako kide 60ko, 70eko eta 80ko hamarkadetan), Argitxu Kantero (ekintzaile kulturala 80ko hamarkadatik aurrera), Frank Suarez (Euskal Kultur Erakundeko ikusgarri arduradun), Ximun Carrere (Kanaldude telebistako zuzendaria), Titika Recalt (ekintzaile kulturala, aktore eta gidoilaria), Anaiz Aguirre (Gabarra Films banaketa etxeko langilea), Peio Cachenaut (zinegilea), Ximun Fuchs (Petit Theatre de Pain antzerki konpainiako zuzendaria eta zinegilea, Gastibeltza filmak ekoiztetxeko sortzailea) eta Elsa Oliarj (dokumentalgilea).

Guzti honi eskerrak, orain arte ezezagunak ziren hainbat film aurkitu eta ezagunak ziren lanen zenbait datu, lehen aldiz ekartzen ditugu paperera. Lurralde esploratu gabe baten lehen kartografia izan nahi dute ondoko lerroek.

\section{Iparraldeko euskaldunak zineman}

Hamarkadatan, Iparraldeko euskaldunek ikus-entzunezkoekin izan duten harremanaren zati handiena, norbanako zenbaitek Euskal Herritik kanpo garatutako ibilbide arrakastatsuak ezaugarritu du. Oraindik, ikus-entzunezkoetara dedikatu nahi duen jendeak kanpora joan behar baldin badu gehienetan, garai batez, ezinbesteko baldintza zen. Hala ere, Euskal Herrian sortutako zenbait pertsonak, garrantzia handiko filmografia garatu dute, bai Frantzian, bai nazioarteko mailan.

Lehenetarik bat, Baionan sortutako Henry Rousell aktorea dugu (Baiona, 1875-Paris, 1946). Historiako lehen euskal filmegile profesionala dateke Rousell, segur aski, zinema mutuaren lehen garaietatik hasi baitzen zuzendari, eta 1913an aktore gisa debutatu eta gero, 1918tik aurrera ("Un homme passa"), hamarnaka film zuzendu zituen Parisen, Louis Delluc, Jean Epstein edo eta Rene Clair bezalako egile ezagunen belaunaldiko kide bihurtuz. "Violettes Imperiales" da haren lanik ezagunena. Beronen bi bertsio egin zituen (1924an eta 1932an), lehena mutua eta bigarrena soinuduna.

Hamarkada bat beranduago hasita, Rousellek baino are karrera oparoagoa egin zuen Harry D’Abbadie D’Arrast baigorriarrak (Buenos Aires, 1897-Baigorri, 1968), Etxauziako seme eta Antoine D’Abbadie euskal mezenaren iloba ttikiak. Parisetik kanpo, Hollywood-era joan zen D'Arrast, eta bertan, Charles Chaplinen gidoilari eta laguntzaile jardun zuen, besteak beste, "A woman of Paris" (1923) eta "The Gold Rush" (1925) maisulanetan. Ondotik, zuzendari gisa plantatu eta arrakasta 
ederra erdietsi zuen mundu mailan, besteak beste, Oscar sarietara izendatua izan zelarik 1930an, "Laughter" filmarengatik. Hogeiko eta hogeita hamarreko hamarkadetan dozena bat film zuzendu zituen, Estatu Batuetan, Alemanian eta Espainian (Borau, 1990).

Ondoko urteetako frantses zinemako aurpegi ezagunetarik bi, Euskal Herrian sortuak izan ziren. Pierre Richard Willim baionarrak, kasurako, "Le Compte de Montecristo" ezagunean Edmundo Dantesen rola jokatuz arrakasta gaitza lortu zuen, eta 30ko hamarkadatik 50ekora, andana bat film protagonizatu zituen; gehienetan, galai ederraren azalean sartuz. Emazteen artean berriz, Martine Carol biarriztarra, garaiko mito erotiko nagusienetarik izan zen Frantzian, Brigitte Bardot agertu arte segurik. Roselllini, Aldrich, Gance eta beste zuzendari handi ainitzekin lan egin zuen Carolek, eta besteak beste, Max Ophuls alemaniarraren "Lola Montes" ezagunean (1955) protagonista izan zen. Montecarloko hotel batean hilik atzaman zuen haren laugarren senarrak.

Genero musikalean, Luis Mariano eta André Dassary euskal herritarrek ere popularitate handia ezagutu zuten urte haietan. Ibilbide ezberdina ukanik ere (Mariano Irunen sortua zen, eta Espainian ere aritu zen bitartean, Dassaryk fama handiena Petainen aldeko "Marechal nous voila" kantuarekin lortu zuen) antzeko proiektuetan ari izan ziren biak, komedia musikal arinetan, eta biek ala biek, euskaldunen irudi folklorizatuaren eraikuntza arketipikoari aurpegia jarri zioten.

Arrunt bestelakoa da, bai estiloz eta bai mailaz, Loleh eta Yannick Bellon ahizpen kasua. Surrealisten argazkilari Denise Bellonen alaba biak, Biarritzen sortu ziren eta banguardiako giro ezkertiarrean hazi zituen amak. Loleh Bellon, teatro eta zinemako gidoilari gisa, eta batez ere, aktoresa gisa aritu zen. Bere gailur artistikoa, Jacques Beckerren "Casque D'Or" filman jokatutako papera izan zen (1952) baina beste zenbait lanetan ere presentzia garrantzitsua izan zuen, tartean, bere ahizparen hainbat filmetan. Yannick Bellon, justuki, zinemagile gisa nabarmendu zen beherahala, "Goemons" labur dokumentalarekin 1948an Venezian saritua izan zenetik. Emazteekin eta feminismoarekin errotik engaiatutako filmografia osatu zuen geroztik, eta nazioarte mailako prestigioa lortu zuen hamarkadatan zehar, gaur egun oraindik irauten duena. Denbora guzti horretan, hainbat sari irabazi ditu, hala nola, 1974ko Donostiako Zinemaldiko Urrezko maskorra, "La femme de Jean" lanarengatik (Roldan Larreta, 2003).

Beste aktore prestigiotsu bat, Michel Etcheverry donibandarra izan zen. Comedie Françaiseko kide sonatua, teatroaz landa, zineman ere andana bat filmetan hartu zuen parte hamarkada luzeetan, Georges Franju, Luis Buñuel edo eta Claude Chabrol bezalako egileekin, besteak beste. Bestalde, 80ko hamarkadan, André Madréren alargunak "Gure Sor Lekua"-ren frantsesezko bertsio bat muntatu zuelarik, berak egin zuen dokumentalaren off ahotsa.

Gidoilarien alorrean, Pierre Apesteguy eta Jacques Celhay izan ziren, XX. mende erditsu hartan profesionalki aritu ziren euskal herritarretako bi. Lehenak, nobelagile gisa hartu zuen fama, baina zinemagintzan ere ibili zen, ez bakarrik gidoigile gisa, aurrerago ikusiko dugunez. Celhayk aldiz, punta puntako lanik ez zuen sinatu, baina bai ordea, arrakasta lortu zuten hainbat film, bai zineman eta bai telebistan. Harena da, esaterako, 60ko hamarkadan oso ezaguna egin zen "Gorri le Diable" seriea, alegiazko euskal kontrabandista bat protagonista zuena. Gaur egunekoen artean, 
Thomas Bidegain xiberotarra da Frantziako gidoilaririk mirestuenetakoa; bereziki, Jacques Audiard-en filmentzat idatzi dituen gidoiengatik. Horrez gain baina, berriki errealizadore gisa ere debutatu du, kritika onak jasoz.

Azken urteotan, ainitz dira zinemara dedikatutako euskal herritarrak, eta langintza gero eta ezberdinagoetan, gainera. Produkzioan, esaterako, Philippe Arrizabalaga, eta bereziki, François Etchegaray nabarmendu dira. Azken honek, Eric Rohmer handiaren azken zazpi filmak ekoitzi zituen, zinegilearen eskuin eskua bilakatuz. Aktoreen artean, Mehdi Nebbou, Christian Abart, Pauline Delpech (sortzez Bidegaray) edo eta Bernard Blancanek beren bidea egitea lortu dute, eta zuzendarien artean, baita Gael Mocaër, Xabi Molia, eta Safy Nebbou ${ }^{3}$ baionarrek, Sandi Louit donibandarrak eta Miguel Courtois zokoarrak, besteak beste.

\section{Atzerritarrak Ipar Euskal Herrian}

Erromatizismoaren gerizan, XIX. mendean zehar euskaldungoari buruz eraikitako imaginario zientifiko, literario eta plastikoak, eta aldi berean, beste lurralde exotiko batzuen aldean, Parisetik iristeko zeuden erreztasunek, aski fite bilakatu zuten Ipar Euskal Herria zinemarentzako eszenatoki pribilegiatu (Martinez, 2016). Urrunegi joan beharrik gabe, hexagonoko sudouest-ak posibilitate bisual eta sonoro erakargarriak eskaintzen zituen (mendia, itsasoa, exotismoa...) ikus-entzunezkoarentzat. Eta hala, XIX. mendean, liburuen eta margoen bitartez Euskal Herria Pirinioetako indioen lurraldea bilakatu bazen, zinemak, erreala erakusteko bere gaitasunari esker, orokortu egin zuen imaginario hori; masa irudi bilakatuz.

Zinemaren asmaketaren garaietatik bertatik ugari izan ziren Ipar Euskal Herrira filmatzera etorritako zinegile ospetsuak, eta tendentzia hori, aroz aro mantendu zen XX. mende osoan. Hala, txoko gutxi dira munduan, hain ttiki izanik, hainbeste aldiz eta hain zinegile handiek erretratatuak izan direnak. Ez hori bakarrik. Zinemak aurrerapen tekniko bat garatzen zuelarik, usu gertatu zen, asmakizun berria probatzera Euskal Herrira jitea zinegile eta ekoiztetxeak. Hala, historiako lehen filmetako bat, Biarritzen filmatu zuten Lumiere anaiek ("La Rochers de la Vierge", 1897). Frantziako lehen dokumental soinuduna ere, euskaldunen lurraldeaz ekoitzi zuen Gaumont ekoiztetxeak (Maurice Champreux zuzendutako "Au pays des Basques", 1930). Hamarkada berean, Louis Lumierek "cinema en relief" 3D teknika asmatu zuenean, "Euskadi" (René Le Hennaff, 1936) dokumentala ondu zuen Pathé-Cinemak, eta 50eko hamarkadan, Europan telebistaren hedatzearen hasmenta sasoian, bere lehen bi erreportajeentzat Euskal Herria aukeratu zuen Orson Wellesek.

Horiek bezala, XX mende osoan, dozenaka dokumental burutu zituzten euskaldunei buruz Frantziatik, Ingalaterratik, Alemaniatik, Suediatik, Estatu Batuetatik, Georgiatik eta beste hamaika lekutatik etorritako zinegileek ${ }^{4}$. Gehienek, arestian aipatu imaginario hori hartu zuten ardatz, dela bere osotasunean, edo dela beronen elementu fetitxeren bat (dantza, pilota, kantua, kontrabandoa, emigrazioa...). Haietarik batzuk bakarrik aipatzearren, honokoak zerrenda genitzake: "Au Pays des Basques" (Maurice Champreux, 1930), "Im Baskenlande” (H. Körösi, 1931), "Euskadi” (René

\footnotetext{
3 Industria frantsesean dozena erdi film luze zuzendu aurretik, Nebbou-k euskarazko bi film labur osatu zituen duela hamabost urte inguru, hegoaldeko aktoreekin. "Bertzea" (2001) eta "Lepokoa" (2003).

4 50eko hamarkadatik aurrera, dokumental zenbait telebistarako ekoitzi ziren, zinema saletarako barik.
} 
Le Haff, 1936), "Im lande der Basken" (Herbest Brieger, 1944) "Der Basken” (daturik ez); "Das Volk der Basken" (daturik ez), "Basques and their Country" (Raymond Bricon-Walt Disney, 1955), "The Basque Countries" (Orson Welles, 1955), "The Basque Pelote" (Orson Welles, 1955) "Le curé basque de Gréciette" (Hubert Knapp, 1958), "Euskal Herrian" (E. Naillon, 1959) "Retour aux Pyrenées" (Jean Faurez, 1960), "Basque River" (Matthew Nathan, 1960), "Le Pays Basque: quelques uns qui parlent le basque" (1974), "Euskadi été 1982” (Otar Ioselliani, 1982), "Pays Basque" (David, Pritchard, 1987), "Hitza hitz, parole de basque" (Enrique Colina, 2010), "Hitz egin. Faire la parole" (Eugene Green, 2015).

Maleruski, haietako asko, oraindik galdutzat ematen dira, eta garaiko prentsa eta dokumentuengatik bakarrik dugu haien berri. Ikusgai ditugunen artean ordea, antzekotasun nabariak dira. Balirudike, euskaldunei buruz eraikitzen duten diskurtsoa, -alegia, Pirinioen eta Kantauri itsasoaren artean kantatu dantzatu eta pilotan jokatzen duen jatorri misteriotsuko herri exotikoaren irudia-, gehiago dela aurreiritzietan oinarritua, lurraldean ikusitakoaren fruitu baino. Bestela esateko, balirudike, zinegileok, euskaldunei buruzko literatura erromantikoa ongi ikasita iritsi zirela errodajera, eta aurretik pentsatuta zuten horixe besterik ez filmatzea deliberatu zutela. Liburuetan eta pinturetan ezagututako mundu mitikoa erretratatzera etorri zirela, eta ez, beren begiekin deskubritzera, desagertzear zegoen eta odolhusten ari zen herria. Horregatik, kasurik gehienetan, beren begirada azalekoa da. Superfiziala. Turistarena (Martinez, 2016).

Fizkioaren alorrean, berdin, askorako eman du Pirinioetako indioen imaginarioak. Eta hor ere, hainbat dira frantses zineman Euskal Herrian edo Euskal Herriaz agertutako filmak. Dokumentaletan bezala, ordea, euskal mito edo klixe batzuk gai hartu eta trama arinen eta pertsonaje eskematikoen bidez egituratutako lanak dira gehienak. "Salbaia onak" bihurtu ziren, hala, euskaldunak; zibilizatu gabeko frantses atzeratu baina bihotz onekoak. Frantzia osoan hedatuko zen euskaldunen irudi hau konfiguratzen, azkarki lagundu zuen fizkiozko zinemak. Irudi folklorizatua, esan gabe doa. Ez bada karikaturizatua.

Halako kanpo begiradaz ekoitzitako filmen artean, ondokoak aipa litezke, besteak beste. "Une noce basque" (1918), "Gachoucha, fille basque" (1921), "Le Chemin d'Ernoa" (Louis Delluc handiak zuzendua, 1921), "Ramuntcho"-ren lau bertsio ezberdin (Lehena, Jacques de Baroncellik zuzendua, 1919; bigarrena, 1938an Rene Barberis-ek, hirugarrena 1948an Pierre Schoendoerfferek eta laugarrena, libreena, "Le Marriage de Ramuntcho" izenpean, 1947an Max de Vaucorbeilek zuzendua), Luis Mariano protagonista zuten pare bat komedia musikal, "L'athlète aux mains nues" (1951ean Iholdin filmatua, Mixel Garikoitzen bizitzari buruz), "Les Mains Liées" (Aita Lhanderen nobela batean oinarritutakoa, 1956), eta telebistarako egindakoen artean, oixtion aipatutako "Gorri le Diable" seriea (1968), edo "Le Refugié" dokufizkio berezia (Danielle Hunebellek 1966an ekoitzia, eta beltz errefuxiatu bat Euskal Herrira ailegatzean bertokoek egiten dioten harrera kontatzen duena).

Begirada sakonago luzatu nahian, 90ko hamarkada hondarrean eta 2000koaren hastapenean, Jean Pierre Grasset errealizatzaileak lau dokumental ("Zazpiak Bat", "Bat-bi", "Hatsa" eta "Ama") eta fikziozko film luze bat mustu zituen: "Lokarri" (2001). Sorlekutik alde egin nahi duen pilotari baten eta euskal kulturak liluratu duen paristar neska baten arteko maitasuna kontatzen zuen Hegoaldeko Basque Films 
ekoiztetxearen koprodukzioa ukan zuen lan honek, eta aktore frantsesekin batera, euskal kulturako kulturgile zenbaiten bigarren mailako partehartzea zuen (Mixel Etxekopar, Eñaut Etxamendi, Filipe Oihanburu,Maddi Oihenart eta zenbait pelotari besteak beste).

Berriki, "Mission Pays Basque" izeneko komedia arin bat estreinatu da Frantzia osoko zinemetan, euskaldungoari buruzko aspaldiko topiko horiek terrorismoaren klixearekin nahastuz, estereotipo regionaletan oinarritutako barre erreza xekatzen duena, Espainian "Ocho Apellidos Vascos" arrakastatsuak bezala, baina euskaldunen estereotipazioan, are urrunago joanez.

Film guztiotan, egilearen jatorria eta garaiko testuingurua gora behera, euskaldunen irudi estereotipatu eta folkloriko bat ematen da. Kanpotik pentsatua eta euskaldunen egiazko errealitatearekin eta kezkekin zerikusi gutxi duena. Alta, hor dago paradoxa, ikus-entzunezkoaren indarrak eta imaginario horren hedapen masiboak, lortu egin dute, azkenean, zenbait euskaldunek ere bere egitea haietaz proiektatzen den irudia. "Museo bizidun" bihurtu dira, Zulaikak esango lukeenez (1994). Beren errepresentazioaren errepresentazio.

\title{
4. Euskaldunen begirada
}

\author{
"No tengo una idea precisa de que haya habido \\ intentos cinematográficos, siquiera aislados, en la otra dirección. \\ $Y$ es pena porque, de haberlos, ahí estarían \\ los verdaderos precedentes de nuestra Cinematografía, \\ subdesarrollada, naciente, como corresponde a todas \\ las manifestaciones nuestras, que pese a estar situadas \\ en un marco de Europa desarrollada tienen necesariamente \\ la connotación tercermundista, tan denostada, de lo que pugna por nacer."
} Antton Ezeiza (1985)

Izan dira, beraz, ikus-entzunezkoetan ibili diren euskaldunak. Eta ikus-entzunezkoak ere, usu ibili da Euskal Herrian. Haatik, Ipar Euskal Herriko ikus-entzunezkorik, are gutiago euskal filmografiarik, ez da esistitu orain arte. Frantziaren egitura zentralistak eta euskal kulturaren egoera minorizatuak esplika lezakete gabezia hau, neurri batean. Baina ez bakarrik. Egoera sozial eta politikoak berdinak izanik, beste espresiobide batzuek -gehiago edo gutiago- garatzea lortu dute XX mende osoan eta XXI. mende hastapenean (kantagintzak, antzerkiak, teatroak edo are eta komunikabideek). Zein da, beraz, Iparraldean mende luzez bertoko filmografiarik ez sortzeko arrazoia? Gure ustez, oixtion aipatutako kultura minorizatu eta periferiko egoeraz gain, ikusentzunezkoen izaera industriala da, dudarik gabe, gakoa.

Hegoaldeko historiak erakusten duen bezala, Euskal Herrian ikus-entzunezkoak sortzea soilik da posible, horretarako baldintzak garatuko dituen egituraketa juridiko eta administratibo azkar bat plantan ematen denean. Halakorik izan ez den sasoietan (autonomia estaturik gabeko urte luzeetan, hots), amateurismoan sortutako ekoizpen heroiko batzuetara mugatu dira ekoizpenak Hegoaldean. Ber gisan, Iparraldean ere, 
halakoxeak ditugu filmak egiteko burutu izan diren saiakerak; amateurrak, idealistak eta isolatuak.

70eko hamarkadatik aurrera, telebistaren eta are, bideogintzaren sorrerak, lekukoek ikus-entzunezkoak ekoitzi ahal izatea erraztu zuten, medioak demokratizatu eta publiko berrietara iritsiz, eta ikusiko dugunez, ikus-entzunezko esperientzia interesgarrienak, arlo horietan garatu direnak dira seguru-aski (bereziki, Maite Barnetcheren telebistarako dokumentalak eta Aldudarrak Bideo-ren esperientzia). Alta, halarik ere, ez da aski izan anbizio artistikoko obrak garatu ahal izateko humus bat sor zedin, eta oraindik gaur, aski desertikoa ageri da Ipar Euskal Herriko panorama.

\subsection{Aitzindariak}

Ezagutzen dugun lehen euskal filmegilea, Edmond Blazy elizgizona dugu. Hendaian sortua, soldadu joan zen Gerla Handira, beste hainbat apez bezala, eta handik itzultzean, euskal kulturaren inguruko ekimen ugaritan murgildu zen. Euskaltzaindiko kidea izan zen, Baionako Euskal Museoko idazkaria, Pilota federazioko lehendakari-ordea eta baita, 1921ean sortu zen Gure Herria aldizkariaren lehen zuzendaria ere. Agerkari honetan hainbat lan idatzi zituen, eta horrez gain "Osaba Amerikanoa" komedia plazaratu zuen euskaraz, eta "La Pelote Basque" liburu famatua frantsesez. Apenas ezagutzen da ordea, horiez gain, bederen bi film burutu zituela 20ko hamarkadan, gaur egun galduak direnak.

Bietako lehena, Euskal Herriari buruzko dokumental bat zen. Guti dakigu hari buruz, salbu paisaiak, ohiturak eta 1922an Gernikan ospatutako Eusko Ikaskuntzaren III. kongresuaren irudiak agertzen zirela. Bigarrena aldiz, fikziozko lan bat zen: "Mirentxu" izeneko "poema zinematografikoa", Pierre Lhande jesuitaren izen bereko nobelan oinarritutakoa. Aski harrigarria da egitasmoa, proiektu konplexua iduri baitu (fikzioa, pretentsio poetikoak...), eta pentsatzekoa baita, Blazy-k baldintza kaxkarrak zituela zinemagile izateko (diru eskasa, formakuntzarik eza eta abar).

Bi filmok, bederen, Eusko Ikaskuntzaren bilkura batean eta Argentinan eta Uruguain proiektatu zirela badakigu. 1924an, Uztaritzeko seminarioa sortzeko sos bila, Hego Ameriketara bidali zituen Baionako apezpikuak Blazy eta Aita Donostia, hango euskaldunengana. Buenos Aires eta Montevideoko euskal egunkarietan ageri denez (Nacion Vasca, La Baskonia, Euskal Erria...), elizgizonek gaualdi bereziak antolatu zituzten euskal komunitateekin hiri ezberdinetan, eta bakoitzak, sorkuntza propio bat eskaini zien bertaratuei. Aita Donostia-ren kasuan, bere konposizio musikalak interpretatzen zituen pianoan. Blazy-k berriz, filmak proiektatzen zituen.

Bereziki aipatzekoa da Buenos Aireseko San Martin teatroan antolatu gaualdia. Julian Ajuria bizkaitar argentinartuak antolatu zuen, eta Blazy-ren irudiak laguntzeko (zinema mutuaren garaian gaude), euskal kantuak interpretatu zituzten abesbatza eta orkestra bat kontratatu zituen ("Un film de asuntos vascos será exhibido en el teatro San Martin”, 1924). Ajuria, ordurako, biziki ezaguna zen Argentinan, bertako zinema nazionalaren aitzindari gisa, eta ekoizle eta banatzaile gisa fortuna handia egina zuen (Lopez Echevarrieta, 1998).

Guzti horiek hola, harrigarria da Blazyren eta haren filmen inguruan den ezezagutza. Zaila da azaltzen nolaz galdu diren, inolako arrastorik utzi gabe, ahanzturaren putzuan. Hipotesi gisa, haren heriotzak izan lezake zerikusirik, euskal historian 
Blazyk duen ezlekuarekin. Ahozko iturri baten bidez jakin dugunez, Uztaritzeko elizako kanpandorrean bere burua urkatu baitzuen, 1941an (Ezkerro, 2015). Apez suizida bat tabu handiegia zatekeen, agian, garaiko Euskal Herrian.

Zenbait urte geroago, beste apez batek ere izan zuen zinemarako proiektu bat: Piarres Lafittek. Azkue Bibliotekan gordetzen diren bere artxiboetan, "Maitagarria" izeneko zinema gidoi bat atzaman daiteke, seguru aski 30eko edo 40eko hamarkadan idatzia (zaila da datatzen), eta itxura guztien arabera, filmatzera iritsi ez zena. Frantses hutsez idatzitako euskal giroko istorio kostunbrista da "Maitagarria"; kanpotiarrek egindako melodrama ruralen antzekoa izateaz gain, bestelako interes berezirik ez duena.

\subsection{Esperientzia arraro bat}

II. Mundu Gerlaren ondoko urteetan, euskal zinemaren historia errotik aldatzeko punduan izan zen Ipar Euskal Herrian. Lekuko jende ezagun batzuek, iduriz, Hegoaldeko errefuxiatu batzuk lagun zituztela, ekoiztetxe bat sortu zuten Saran: "Euzko Films". Alta, enpresak ez zuen luze iraun eta egitasmoak bizi laburra izan zuen.

Jadanik lerrootan agertua zaigun Pierre Apesteguy idazle eta gidoilaria izan zen Euzko Film-en zuzendari teknikoa, eta zuzendari orokorra berriz, Paul Dutournier euskalzale ezaguna; handik gutxira Sarako auzapez bilakatuko zena. Dutorurnierek rol tipi bat jokatu zuen 1937an Saran filmatu zen "Ramuntcho" filman (René Barberis-ek zuzendutako bertsioan), eta akaso, esperientzia hartatik heldu zitzaion zinemagintzarako grina.

Pentsatzekoa da, ekintzaileok, abentura abiarazteko sos kantitate eder bat atzeman zutela nonbait. Izan ere, Pariseko Champs Elisées-etan bulego bat ireki zuten, eta Euzko Films, frantses industriako ekoiztetxe gisa jardun zen martxan egon zen urte laburretan. Hiru film komertzial ekoitzi zituen: 1948an, Pierre Apesteguyk idatzitako "Les souvernirs ne sont pas á vendre" (Robert Hennion-ek zuzendua) eta "Les eaux troubles" (Henry Calef-ek zuzendua) melodrama frantsesak, eta 1949an, turismoari begira burututako "Au Pays Basque avec Luis Mariano" (Apesteguy-k berak zuzendua). Tituluok ikusirik, iduri du, frantses publikoari begirako proiektua zutela jomuga. Frantses zinema egin gura zutela, alegia. Hala ere, ikertzekoa da gaia; bereziki, proiektuan parte hartzen omen zuten Hegoaldeko errefuxiatu abertzaleen paperari dagokionez.

Enpresa itxi aurretik, Euzko Films enpresak Ilbarritzeko gaztelua (Bidarten) erosi eta bertan zinema estudio bat muntatu nahi izan zuen, nolabaiteko "euskal hollywood" bat sortuz. 1984an Dutournier-ek Jose Maria Unsain historialariari esan zionez, Mexikon bizi ziren euskaldun dirudun batzuk proiektuaz interesa zitezen lortu zuten, baina azken mementoan, atzera egin zuten eta sosik gabe, ezin izan zuten egitasmoa gauzatu (Unsain, 1985).

\subsection{Gure Sor Lekua}

Ipar Euskal Herrian sekula egin den filmarik garrantzitsuenetakoa, 1956an Hazparnen estreinatu zen "Gure Sor Lekua" dugu, André Madré-k ekoitzi eta zuzendua, Jean Elizalde Zerbitzari apezaren gidoiarekin. Alde batetik, historiako euskarazko 
filmarik zaharrena delako. Bestetik, amateurismoz, auzolan dosi handi batekin eta Madré-ren ekimen pertsonal eta idealista hutsetik sortua izan arren, ordu eta erdiko kalitate ederreko lana delako; egileak frantses armadan koronel postua izateari esker, baldintza tekniko onetan egina.

Ume-umetatik sorlekutik urrun ibilia baitzen, herrimina zeukan Madré abiadoreak eta 50eko hamarkadan, Parisen bizi zela, errefuxiatu abertzaleekin kurutzatu eta sentimendu hori diasporako beste euskaldunekin partekatzean euskal film bat egiteko ideia etorri zitzaion.

Gerora idatzitakoei eta prentsan argitaratutakoei erreparatuz gero, ez dirudi "Gure Sor Lekua" burutzean bere xede nagusia euskara zinemara ekartzea zenik (Madré, 1953; Duhour, 1956; Lahina, 1956). Euskararen aldeko ekintza bat burutzea baino, Madré-k zuen helburua, (diasporako euskaldunak gogoan) euskal film bat osatzea zen: goitik behera euskalduna izango zen film bat. Estreinaldirako gonbidapenetan eta prentsan erabili zen espresioa baliatuz: "\%100 basque" ("Premiere Mondiale du film Sor-lekua entierement en basque", 1956).

Madré-rentzat, bere lana funtsean hiru elementurengatik zen euskal filma: Euskal Herriaz eta euskaraz ari zelako (edukiarengatik), euskaldun batek egina zelako (egilearen begiradarengatik) eta euskaldunentzako egina zelako (ikusleen begiradarengatik). Hala uler daiteke "Gure Sor Lekua”-ren hizkuntza (bai hitzez, bai idatziz) euskara izatea.

Edukiaz gain, egileak ere euskalduna behar zuen, filma \%100 basque izateko. Eta hori, Madré-ren aburuz, begiradak ematen zuen. 1953ko ekainean Zerbitzari-ri gutun batean ziotsanez, eskas zituen Euskal Herria barne begirada batekin erakutsiko luketen filmak. Sutan jartzen zuten kanpo begirada batez egindakoek:

\begin{abstract}
Vivant depuis longtemps loin du Pays Basque, je sais tout le plaisir que j'éprouve à voir de temps en temps sur un écran un paysage ou une scène de chez nous. Mais je sais aussi les colères que je rentre devant les films idiots ou ratés que l'on projette, qu'ils soient payés par le syndicat d'initiative ou les plages pour les réclames, ou qu'ils soient tournés par des cinéastes qui ne connaissent rien du Pays Basque ou qui sont simplement de mauvais opérateurs (Madré, 1953).
\end{abstract}

Haren arabera beraz, Euskal Herriari buruzko filmek, euskaldunek ikusteko baziren, "barne begirada" bat eskatzen zuten. Euskaldun baten begirada. Eta horretantxe saiatu nahi zuen.

Azkenik, Madré-ren ustez, xede zuen ikuslegoak egingo zuen filma han edo hemengo. Egilearen eta ikuslearen begiradek bat egiteak borobilduko zuen filmaren nongotasuna. Errodajea bukatzen ari zela, 1955ean "Peut on réaliser un film basque?" izenburupean Pariseko Euskalzaleen Biltzarrean egindako konferentzian, hala zioen: "Zoin ekei edo molde hauta? Zertarako eginen den, edo norendako: hortan da ihardespena. Ze xederentzat egiten den! Kanpotiarrentzat balin bada, ez da hain minbera izaiterik. Egiaren orde, iduripena hola aise, hura gogoan, han iretsiko dute lorian" (B.D., 1955). 
Emaitza ordu eta erdiko koloreko dokumental amateurra izan zen; garaiko Iparraldeko euskaldun fededun ereduko herritar baten bizitza kontatzen zuena, jaiotzatik ehorzketaraino, urratsez urrats.

Harrigarria badirudi ere, "Gure Sor Lekua" munduko hainbat lekutan ikusi ahal izan zen zenbait urtez, beti ere zirkuitu komertzialetik kanpo, lekuko euskal komunitateek antolatutako gaualdi berezietan (San Franciscon, Parisen, Dakarren...). Euskal Herrian ere, 1956 eta 1957 artean, badakigu, bederen, Hazparnen, Baionan, Uztaritzen, Azkainen, Beskoitzen eta Aiherran proiektatu zela, gehienetan herrietako gazteria giristinoak (Eskualdun Gazteria eta antzeko taldeek) antolaturik (Martinez, 2015).

\subsection{Zinema amateurraren zabaltzea}

Madré-k "Gure Sor Lekua" burutu zuen garaian, 16 mm-tan filmatzeko kamarek zabalpen handia lortu zuten, eta horrek, merketu eta erreztu egin zuen bestelako proiektuen filmaketa. Aldi berean, kamara askoz arinagoak asmatu zituzten urte haietan, txikiagoak eta eramangarriagoak, eta horrek, filmaketa esperimental eta amateurren ugaltze handi bat ahalbidetu zuen.

Zinema egiteko modu berriak sortu ziren munduko leku ezberdinetan. Free Cinema sortu zen Erresuma Batuan, Cinema Direct-a Quebec-en... Ipar Euskal Herrian, egoera ez zen hortaratu, baina hala ere, filmaketa amateurren ugaritze bat eman zen.

Uztaritzen errefuxiatuta bizi zen Ynchausti familiaren seme zaharrenak, Antonio Ynchaustik, hainbat film errodatu zituen 40 eta 50eko hamarkadetan euskal gaiei buruz. 1948an, Eusko Ikaskuntzak Biarritzen antolatutako VII. Kongresua filmatu zuen, eta 1954an Baionan antolatutakoa; euskal kulturaren biziraupenarentzat garrantzi handikoak izan ziren hitzorduak, biak ala biak. Herrietako jaiak, pilota partidak, uso ihizia eta beste zenbait herri usaia ere hartu zituen Ynchausti gazteak, 16 mm-ko Bell\& Howell kamera batekin. Filmaketa guzti horiek, muntatuketarik eta titulurik gabe daudenak, Ynchausti familiaren etxean kontserbatzen dira, eta gutxi batzuk baino ez dira ezagunak (Ynchausti, 2015).

1957ko euskal prentsan irakur daitekeenez, bestalde, "Hegaluzia" izeneko film bat ari zen filmatzen Robert de Fontaine, Donibane eta Ziburuko arrantzaleen hegaluzearen kanpainei buruz (garai hartan, Dakar aldera joaiten hasi berriak ziren) eta oro har, itsasgizon bizitzaz ("Filma berri bat", 1957). Haren berririk ordea, ez da orainokoan. Badakigu ere, herriko jendearen lekukotzei esker, sasoi hartan, Hoztan izan ziren toberak filmatu egin zituztela, film amateur bat burutuz. Maleruski, haren arrastoa ere galdua da.

Urte haietan, bestalde, zinema salak ainitz hedatu ziren; eta barnekaldeko hainbat herri txikitan ere filmak ikusteko aukera zabaldu zen. Gehienetan, elizari lotutako lokaletan izaten zen; patronaje-en geletan, edo parropiaren saletan. Urte luzeetan zinemagintzarekiko uzkur eta mesfidati agertu ziren apezek, zazpigarren artearen indarrari ezin aurre eginez, beren gain hartzea erabaki zuten. Haien eskuetatik pasako zen, hala, ikusleek kontsumituko zutena, modu horretan, kontrol sozialari eutsiz.

Elizaren gerizan, herrietako zinemotan, film komertzialen aurretik, eta Frantzia mailako "Les actualités" ondotik, herri bizitzari buruzko filmaketa laburrak pasatzen hasi ziren urteotan. Usu, lekuko elkarte katolikoetako gazteek filmatuta, bertoko 
gertaerak erakusten zituzten, nolabaiteko "berri-emaile" gisa; behi lasterrak, pilota partidak, prozesioak, merkatu egunak, medikuak erositako auto berriaren irudiak.... Badakigu, bederen, Hazparnen eta Donapaulen izaten zirela halakoak (Rekalde, 2014; Etxaluz, 2017), eta ez da dudarik, ez zela han bakarrik izanen.

\title{
4.5. Pantaila txikian euskaraz
}

Zinema salan ikusitako hurbiltasuneko irudi horiek, nolabait, gerora emankorra izango den bide baten aitzindaritzat hartu daitezke. Egia bada ere, Iparraldean ez dela film handirik izan orain arte, hurbiltasunetik eta herrikoitasunetik burutu du populuak bere buruaren errepresentazio filmikoa: behinolako film ttiki haiekin bezala, hainbat urte beranduago Aldudarrak Bideo elkartearekin eta Kanaldude Herri telebistarekin.

16 mmko filmen garaiaren eta bideoaren agerpeneran artean ordea, telebistaren asmakuntzak ere, ekarri zuen, Ipar Euskal Herrian euskaldunek eta euskaldunentzako pentsatutako filmak sortzeko zirrikitu bat. Ez alferrik, telebistarako lehenengo euskarazko saioak (dokumental laburrak ere deitu ahal zaie, beldurrik gabe), France3 katerako Maite Barnetxe bidarraitarrak burutu zituen, Hegoaldean ETB sortu baino 15 urte lehenago. Euskarazko zinemaren lehen urratsak ("Gure Sor Lekua"rekin) Iparraldean eman ziren ber, euskarazko telebistarenak ere, hala gertatu ziren.

1971ko urriaren 4an, arratsaldeko 18:30etan puntuan, Mattin bertsolaria agertu zen Ipar Euskal Herriko etxeetako telebistetan. Laneko arropekin, Ahetzeko bere etxaldearen pentze batean zutik, ezker eskua gurdi batean zuela ondorengo bertsoa kantatu zuen:

\author{
"Telebistan'e hasi zauzkigu eskuaraz emankizunak \\ lan hortarako etorri zaizkit gizon batzuk jakintsunak \\ izate hortaz poztu zaitezte adiskide ta lagunak \\ bihotz erditik agurtzen ditut beira dauden eskualdunak".
}

Horiexek dira telebistaren historiako lehen euskarazko emankizuneko hastapeneko berbak. Euskarak telebistan leku (txiki) bat lortu zueneko lehen agurra. Soinua zineman entzun zen lehen aldia, "The Jazz Singer" filman izan baldin bazen, esan genezake, pantailako txikiko gure Jazz Singerra, Mattin izan zela. Handik goiti, makinatxo bat aldiz agertuko zen berriz Mattin, garaiko euskal kulturako beste pertsonaia inportante gehienak bezala, bi asterik behin, larunbat eguerditan emititzen zen hamabost minutuko erreportajean.

Telebista 1957 hondarrean iritsia zen Akitaniara, Brouillac-en (Bordele kanpoaldean) emisore bat ezarri zelarik. Alta, emeki emeki sartu zen "leiho txikia" euskaldunen etxeetan. 1971an, Aquitaine-Bordeaux estazioaren emisioen barnean, euskarazko saio labur batzuk emititzeko bidea ireki zen. Jacques Chaban-Delmas lehen ministroak iragarritako zabalpenen ondotik, Michel Inchauspé diputatu garaztarrak Asanblean eskatu eta lortu zuen euskarazko emankizunentzako baimena, eta hala, Bordeleko zentroak proiektua martxan jarri zuen, beti ere, kontrol pean. Bordeleko unibertsitatean euskara katedra zuen Jean Haritschelar irakaslea, ekimenaren 
"erantzule moral" izendatu zuten, eta 1970ko irailean argitaratutako aurre-informe batean, emankizunetan pilotari, herri kirolei eta euskarazko teatroari leku berezia ematea gomendatu zen (Cheval, 2005).

Frantses irratian euskarazko emisioez arduratzen zen Maite Barnetche kazetaria hautatu zuten euskarazko saio berriaren zuzendari, baina gainontzeko lan guztiak, grabaketa egunetan Bordeletik etortzen zen lau teknikariz osatutako ekipa batek eramaten zituen. Hastapenean, Barnetche-k ez zuenez ikus-entzunezko lengoaiaren ezagutzarik, errealizadore bat jarri zioten ondoan eta haren laguntzarekin osatu zituen lehen saioak; ofizioa ikasi zuen arte.

Urte haietan, orotara 300 bat emanaldi emititu ziren, orotara 75 ordu inguru, eta Ipar Euskal Herriko bizitza kulturalaren ikus-entzunezko lekukotza bizia bihurtu zen emankizuna, Patricio Guzmanek zinema dokumentalari ematen dion zentzuan (2013), euskaldunen familia albuma.

Haren heina, itsasoan tanta batenaren pareko zen. 1978an, FR3 Aquitaine-ren urte osoko aktibitatearen $\% 4$ baino ez zuten suposatzen. Eta edukiz ere mugatua zen "Eskual Herria orai eta gero". Politikaren beldur, emankizuna martxan jartzeko baldintzetako bat, aktualitateko gairik ez ikutzea izan zen hasieratik (Gasteiz, 1979; Arbelbide, 2002). Alta, zenbait kasutan, aktualitatea nahi eta nahi ez agertu zen. Esaterako, ikastolei zenbait saio osorik eskaini zitzaizkien. Gainontzekoan, kultur gertaerek (antzerkiek, pastoralek, kantaldiek, bertso saioek, literaturak), tradizioaren ikuspegitik begiratutako errealitate sozialek (arrantza, laborantza....), herri eta bailaretako historiak edo eta aiton-amonen lekukotzek bete zituzten ordu gehienak. Zentzu horretan, harribitxia da Barnetxek urtez urte sortu zuen irudi funtsa. Kasu askotan, ikus-entzunezko lekukotza bakarra. Etxahun Iruri, Xalbador, Mattin eta Xanpun bertsolariak; Pantxoa eta Peio, Niko Etxart, Maite Idirin, Errobi, Ortziken, Zazpiribai, Erramun Martikorena, Etxamendi ta Larralde, Estitxu eta Eltzegor musika taldeak; Piarres Lafitte, Telesforo Monzon, Piarres Larzabal, Roger Idiart, Piarres Xarriton, Louis Dassance, Jean Haristchelar eta Txomin Peillen kultur gizonak; Dongaitz, Durruty, Gaby, Lemoine eta Boudon pilotariak; lehen ikastoletako haur, guraso eta irakasleak... guzti horiek eta gehiago, behin eta berriz agertzen dira urte haietako ikuskizunetan, euskal kulturaren familia album paregabea osatuz.

\subsection{0 eta $80 \mathrm{ko} \mathrm{hamarkadetako} \mathrm{filmak}$}

70eko eta 80ko hamarkadetan, telebistan Maite Barnetchek bide egiten zuen bitartean, zinemaren teknikek beste jauzi bat egin zuten medioen "demokratizaziorantz". Super8 formatuko kamaren eta bideokamara domestikoaren sorrera eta zabalpen masiboak, milaka pertsonaren esku jarri zuen filmaketak egiteko ahala, sekula lehenago ez bezala. Bestalde, Euskal Herrian bizi zen egoera politiko zapartatsuak, mugimendu kulturalaren azkartzea ekarri zuen hainbat arlotan, eta horrek ere, izan zuen oihartzunik ikus-entzunezkoen sorkuntzan.

Hegoaldean ekoitzitako hainbat dokumentaletan, Iparraldea filmatua izan zen. Kasu batzutan, atzerritarrenetik sobera bereizten ez zen begirada folkloriko hutsez ("Ama Lur" ezagunean bertan, urrunago joan gabe). Euskal Herriari buruzko irudi klixeetan, Zuberoko dantzariak falta ezin balira bezala. Beste kasu batzuetan ordea, ikuspegi nazional batetik abiatuta, lekuko errealitateak sakon aztertu nahia ageri da. 
"Ikuska" dokumental sailean (1978-1984), esaterako, argi ikusten da hori. Antton Ezeizaren koordinaziopean, hegoaldeko hogei errealizadorek egindako hogei dokumentalek osatzen duten euskarazko seriea izan zen "Ikuska", kalitate tekniko bikainekoa, eta bertako bi film iparraldeko gaiei buruz ondu ziren: lehena, Donibane Lohitzuneko arrantzaz, eta bigarrena, barnealdeko artzaintzaz. Biak, Antton Ezeizak zuzendu zituen eta ohiko ikuspegi bukolikotik atereaz, arrantzaleen eta artzainen eguneroko arazoak zituzten ardatz, ikuspegi sozial batetik. Errealizadorea eta ekoizleak hegoaldekoak izan arren, filmotan, lekuko hainbat jendek kolaboratu zuen, maila tekniko zein artistikoan; besteak beste Kristiane Etxaluz, Jose Goitia, Marzel Etxehandi, eta Jokin Apalategi eta Joxe Manuel Pagoaga bezalako errefuxiatuek.

Beste proiektu interesgarri bat, "Xalbador gaztain kormutxa" da (1981), Juan Miguel Gutierrez errenteriar dokumentalgile amateurrarena. Super-8 formatuan eta medio izugarri urriekin burutua izan arren (bukaerako kredituak, esaterako, folio xuritan eskuz idatzita agertzen dira) oso lan txukuna eta duina izan zen. Bertan, Joxe Mari Aranalde eta Emile Larreren interbentzio txiki batzuk ikusiko ditugu, baina film osoan pisu nagusia, Xalbadorren gertukoek eramaten zuten: haren familiak eta lagun bertsolariek. Gutierrezen hitzetan (2014): "Xalbador hila zen eta ez genuen haren irudi bakar bat ere; ez kantuan, ez artzain lanetan ez eta etxean; audio grabazio batzuk baino ez genituen, eta argazki zaharren bat. Horregatik, harengana eta haren mundu poetikora hurbiltzeko modurik egokiena gertukoei erreparatzea izango zela pentsatu nuen; eta lehen-lehenik emazte Leoniri, bertsolaria zen seme Mixeli, eta alaba Henrietteri."

Filmak nahiko zabalpen ona izan zuen, zirkuito komertzialetatik kanpo erakutsi zela kontuan hartuz. Hurrengo urteko Urepeleko omenaldian estreinatu zen, eta ondoren, hainbat kultur etxe eta elkartetan. Gutierrez (2014): "Emanaldiak egiten zirenean, geuk eramaten genuen guztia; proiektorea, soinu-ekipoa... Gonbidatzen gintuztenek lokala eta maindire zuria jartzen zuten, ez besterik".

80ko hamarkadan, bertako jendeek egindako beste bi laburmetrai ageri zaizkigu; estiloz eta aurrekontuz, arras ezberdinak. Batetik, 1983an, Kristiane Etxaluzek burututako "Zuraren adarra" film poetiko esperimentala, eta bestetik, 1986an Koxe Alberdik zuzendutako "Pitxu, alfer haundia" animaziozko laburmetraia.

Etxaluzen lana, 50 minutuko "bideo antropopoetikoa" zen, Pauen sortu zen OREP ( Office Régional d'Education Populaire) erakundeak ekoitzia. Kamara, soinua eta muntaia, Paueko teknikalari batek hartu zituen bere gain, eta auzolan izpirituan, lagun andana bat parte hartuarazi zuen Etxaluzek, aktore eta bestelako lanetan. Haren asmoa, osoki euskaraz pentsatutako hiru film burutzea zen: lehena arbolari (zurari) buruz, eta hortik aurrerakoak, ibaiari (urari) eta haizeari (aireari) dedikatuak. Horrekin, egilearen esanetan, elementuok euskal kosmogonian zuten paperaz gogoetatu nahi zuen, euskal imaginario kolektiboan bilaketa lan bat eginez. Alta, azkenean, lehen filma baino ez zuen burutu (Etxaluz, 2017).

Dozena erdi bat aldiz pasatu zen "Zuraren adarra" Iparraldean, herri ezberdinetako Euskal Kultur Asteetan, eta emazteen aldeko gaualdi batzuetan. Horrez gain, 1983ko Donostiako Zinemaldian parte hartu zuen; bideoarte sekzio baten barnean. Maleruski, esistitzen zen kopia bakarra, galdu egin zuen duela 10 urte inguru, Baigorrin, uholdeek eramanik. 
"Pitxu, alfer haundia", bestelako lana da. Standard komertzialen baitan burututako ekoizpena izan zen, Euskal Herriko Kultur Zentroaren, CNCren ${ }^{5}$ eta Eusko Jaurlaritzaren laguntza ukan zuena, besteak beste. Pitxuren herri kondairatik abiatuta, 11 minutuko marrazki bizidun ederra sortu zuen Koxe Alberdi errenteriarrak, kolaboratzaile talde ederraz inguratuta: Argitxu Kantero, Itxaro Borda, Mikel Antza, Peio Berhokoirigoin, Pantxoa Etxegoien... Gonzalo Etxebarria artista izan zen paisaialaria, eta Michel Portalek egin zuen musika.

\subsection{Bideoaren garaia}

90eko hamarkadaren sarrerak, Hegoaldean, euskal zinemarentzako, hamabost urte iraun zuen lehortearen hasiera ekarri zuen. Iparraldean ere, beraz, ezinbestean, hutsune hori nabaritu, eta aurreko urteetan pilatutako energia eta esperientziek eten bat izan zuten. Haatik, sasoi hartan, denborarekin gako bihurtuko den egitasmo bat sortu zen: Aldudarrak Bideo proiektua.

Aldudarrak kultur elkartearen adar bezala sortua, 1997an abiatu zen Aldudarrak Bideo, barnekaldean ikus-entzunezkoen bidez euskara bultzatzeko xedearekin, lekuko euskaltzale batzuen eta ikus-entzunezko ikasketak egin berri beren lanbidea etxetik hurbil eraiki nahi zuten gazte batzuen elkarlanetik (Carrere, 2017). Filosofia herrikoi eta parte hartzaile batekin, aski fite hasi ziren bideoak ekoizten, eta 1999an, beren lehen dokumentala burutu zuten: Mikel Erramuzperen "Sorlekua utziz geroz", Ximun Carrere eta Nicole Alixek errealizatuta.

Geroztik, "Kanaldude Herri Telebista" bihurtuta, gertuko informazioa jorratzen duten bideo eta emankizunez gain, beste hainbat dokumental ekoitzi dituzte ("Jeunes Basques en Iparralde", 2001, “Ttipi ttapa", 2004, "Orreaga", 2008....).

Urteak joan ahala, interneten bideoak hedatzeak, telebista klasikoko kate batzuetan bere edukientzat leku bat egiteak (TVPI eta Hamaikan, besteak beste) eta enpresaren egonkortze eta azkartzeak (2010etik, dozena erdi langile dituen kooperatiba da), Aldudarrak bideo, Iparraldeko ikus-entzunezko ekosistemaren aktore nagusietakoa bilakatu dute.

\subsection{Gaur egunerako bidean}

Azken hamar-hamabi urtetik hona, euskal zinemak loraldia bizi duela entzun ohi da. Hegoaldean segurik, 2015etik, urtero bederen euskarazko fikzio luze bat eta dozena erdi dokumental plazaratzen dira, eta baita film labur andana bat ere. Goraldi horren arrazoiak askotarikoak izan daitezke, baina bik bederen, argiak dirudite: batetik, euskaraz alfabetatuta dagoen eta hizkuntza hortan naturalki jarduteko gai den belaunaldi baten iristea, eta bestetik, instituzioetatik eta ETBtik bultzatutako politika publikoen aldaketa, urtero diru partida emankorrak emanez euskal filmen proiektuei.

Loraldi honek ez du, gaur arte bederen, parekorik izan Iparraldean. Areago, duela gutira arte, Hegoaldeko mugimenduarekiko deskonexioa erridikuluraino luzatzen zen hainbat kasutan. Esaterako, traba administratiboen arazoengatik, Donostian ekoitzi euskarazko filmak Baionako zinemetan ikustea, zailagoa zen Bartzelonan edo Sevillan ikustea baino.

\footnotetext{
5 Centre National de Cinematographie.
} 
Urteen poderioz, emeki emeki, dinamika berriak sortu dira lurraldean eta horiei esker, gaur egun, ikus-entzunezkoen inguruko ekosistema bat osatzeko lehen urratsetan egon gaitezke. Hasteko, Hegoaldean baino askoz maila apalagoan bada ere, Iparraldean ere, sortzaile belaunaldi baten arribatzea senditu daitekeelako azken urteotan. Gauzak egiteko gogoa duten eta kasu gehienetan, euskaraz filmatzeko gai diren jendeak dira; orain arte, beharrez, maila amateurrean mugitu behar izan dutenak oro har. Horien artean aipa litezke Eñaut Castagnet, Ximun Fuchs, Eki Pagoaga, Iban Rusiñol, Juhane Dascon, Ibai Agirrebarrena, Miriam Aizager, Peio Cachenaut, Titika Recalt, Audrey Hoc, edo eta, beste maila batean, Elsa Oliarj, Maiana Bidegain eta Sylvie Garat (kanpoan bizi diren euskal profesionalak izanki, Euskal Herriko gaietaz filmatu ohi dutenak). Eskura zituzten ahalak ikusirik, kasu batzuetan sortzaileek lortutakoa ez da txikia izan. Hala, 2012an "Xora" estreinatu zuen Peio Cachenautek, Iparraldeko lehen fikziozko euskal film luzea, eta bestalde, 2017an, lehen aldiz, Iparraldeko film luze bat ikusten ahal izan da Donostiako Zinemaldian: Ximun Fuchs eta Eñaut Castagnet-ek frantsesez filmatutako "Non" (ez). Bigarrenik, euskarazko filmen gose ziren herritarren eskutik, instituzioen beha egon gabe, Zinegin euskal zinemaren festibala sortu zen duela bost urte Hazparnen, eta gaur egun, urteroko zita garrantzitsua bihurtu da, ez bakarrik Iparraldean baina Euskal Herri mailan.

Hirugarren, Kanalduderen indartze inportante bat gertatu da azken urteotan, eta emeki emeki, filmen ekoizpen eta ko-ekoizpenean parte hartuz, esperientzia pilatu du. Horrez gain, laster, telebista difusore estatutua lortu eta Akitania eskualdearekin konbenio bat sinatuz, urtero sorkuntza ekoizpenetan inbertitzeko partida bat izango duela dirudi. Konbenio horrek, egikarituko balitz, jauzi kualitatibo bat suposatuko luke euskal ekoizpenentzat, finantzazio iturri izateaz gain, Bordeleko ECLA-Aquitaine ${ }^{6}$ eta Pariseko CNCren dirulaguntza deialdietara aurkezteko parada emango liekeelako.

Aldi berean, zenbait ekoiztetxe sortu dira; Gastibeltza Filmak, La Fidele eta Ateka films, eta, EKE eta Atalante zinemagela baionarraren hitzarmen bati esker, urtero Iparraldeko zinema geletan euskal film bat edo bi banatzea xede duen Gabarra films banaketa etxea ere martxan eman da.

Bukatzeko, Iparraldeari lehen aldiz instituzionalizazio ofizial bat aitortzen dion Euskal Herri Elkargoaren sorrerak, euskarari eta kulturari dagozkion politika publikoen berdiseinatze bat ekarriko du datozen hilabeteetan. Zentzu horretan, EKE ${ }^{7}$ eta $\mathrm{EEP}^{8}$ erakundeak hasiak dira, ikus-entzunezkoak babestu eta bultzatzeko ardurak ber-aztertu eta sektoreko aktore ezberdinekin partekatzen.

\section{Ondorioak}

Artikulu honetan, Ipar Euskal Herria eta ikus-entzunezkoen arteko harremanaren erretrospektiba historikoa burutu dugu. Lehenik, zinemaren sorreratik gaurdaino, filmagintzan jardun duten Iparraldeko euskaldunen errepasoa egin dugu; ondotik, atzerritar filmegileek Ipar Euskal Herrian zuzendutako lanak eta haietan islatutako imaginarioa aztertu, eta finean, Iparraldeko euskaldunek eurek, sorlekuan ekoitzitako filmetaz okupatu gara. Horri esker, orain arte ezezagunak zenbait filmen erre-

\footnotetext{
6 Akitania eskualdeko kultur sorkuntza sustatzeko egitura publikoa. "Ecrit Cinema Livre Audiovisuel".

7 Euskal Kultur Erakundea.

8 Euskararen Erakunde Publikoa.
} 
ferentzia ekarri dugu, lehen aldiz, paperera (Blazy-ren lanak, "Maitagarria", "Hegaluzia"...) eta aldi berean, jadanik aipatuak ziren zenbait filmeren inguruko datu berri ugari aurkitu ditugu.

Konstatatu ahal izan dugun lehen gauza da, artista handi asko esportatzeaz gain, Ipar Euskal Herria, hainbat aldiz aitzindari izan dela ikus-entzunezkoen historian; hala nola, historiako lehen filmeen eszenatoki gisa ("La Rochers de la Vierge", 1896) edo aurrerapen teknikoen probaleku gisa (Lehen film soinuduna - "Au Pays des Basques", 1930-, 3Dko lehen filmaketena, - "Euskadi, 1936"-, edo telebistako lehen erreportajeak, - "The Basque Countries", 1955-). Eta aitzindaritza hori, euskal ikus-entzunezko historian ere eraman izan duela; besteak beste, euskarazko lehen filma ("Gure Sor Lekua") eta euskarazko lehen telebista-saioa ("Euskal Herria orai eta gero") ekoitziz. Horrekin batera ordea, argiki ikusi dugu, aroz aro, ezinezkoa izan dela Ipar Euskal Herrian bertoko filmagintza bat sortzea, eta horrek, talentuen erbesteratzeaz gain, amateur mailako zenbait saiotara mugatu duela orain arteko filmografia.

Jorratu ditugun gaiak zehazkiago tratatuz, lehenik esan daiteke, historiako aro guztietan, ikus-entzunezkoen goi mailan lan egin duten andana bat Iparraldeko euskaldun agertu zaizkigula, eta tendentzia areagotuz, gaur egun, gero eta ugariagoak eta anitzagoak direla mundu horretan sartzen direnak. Profil eta bide arras ezberdinak dituzte denek, baina, ezaugarri amankomun bat ere badute: deserrotzea. Lerrootan aipatu ditugun pertsonalitate guztiek sorlekutik joan behar izan dute beren profesioa gauzatzeko.

Bigarrenik, esan daiteke, oso ugariak direla, hala dokumentalean nola fikzioan, Ipar Euskal Herriko gaiak hartu dituzten atzerriko ekoizpenak. Haietako gehienetan, egilearen jatorria eta garaiko testuingurua edozein izanik ere, euskaldunen irudi hertsi, partzial, estereotipatu eta folkloriko bat eman da, aurrejuzkuetan oinarritua, eta tokiko errealitatearekin zerikusi gutxi duena.

Bukatzeko, lekuan bertan ekoitzitako filmeei dagokienez, baldintza kaxkarretan mustutako lan amateur, idealista eta isolatuak baino ez ditugu aurkitzen, zinemaren hasmentatik gaurdaino. 70eko hamarkadatik aurrera, telebistaren etabideogintzaren sorrerak, euskaldunek ikus-entzunezkoak ekoitzi eta kontsumitu ahal izatea erraztu zuten, Maite Barnetcheren telebistarako dokumentalen eta Aldudarrak Bideo-ren esperientzia interesgarriek erakusten duten bezala, baina halere, ez da aski izan anbizio artistikoko obrak garatu ahal izateko baldintzak sortu eta filmagintza jarraitu bati bide emateko. Hala, baitezpadakoa ageri da, horretarako, egituraketa juridiko eta administratibo azkar bat plantan ematea.

Esperantzarako tarterik bada, ordea. Gaur egun, inoiz baino hobea dirudi egoerak, Ipar Euskal Herrian ikus-entzunezko ekosistema bat egituratzeko. Euskaraz eta Euskal Herrian filmatu nahi duen egile belaunaldi berri baten iristeak, Kanaldude telebistaren zabaltze eta indartzeak, herrigintzatik sortutako Zinegin festibalaren sendotzeak, euskal filmen ekoizpen eta banaketaz okupatu nahi duten egitura ttipien jaiotzak, eta lurraldearen instituzionalizazioak ekarriko duen politika publikoen berdiseinatzeak, norabide horretan garamatzate. Osagai guzti horiek kontuan izanda, balirudike, historian lehen aldiz baldintzak sortzen ari direla gaur egun, Iparraldean filmak egin ahal izateko. Hala izango den, denborak, eta bereziki, hemendik goiti agente ezberdinek emanen dituzten pausuek esango dute. 


\section{Erreferentzia bibliografikoak}

Aguirre, A. (2017, agorrilak 2). Elkarrizketa pertsonala.

Amezaga, J. (1996). Herri kultura: euskal kultura eta kultura popularrak. Leioa: UPV/EHU.

Arbelbide, X. (2002): Maite Barnetxe. Bidegileak saila. Gasteiz: Eusko Jaurlaritza.

B. D. (1955). Parisetik. Elgar: journal mensuel des basques de Paris.

Borau, 1 (1990). El caballero D’Arrast. Donostia: Donostiako Nazioarteko Zinemaldia.

Cachenaut, P. (2017, agorrilak 3). Elkarrizketa pertsonala.

Carrere, X. (2017, agorrilak 30). Elkarrizketa pertsonala.

Cheval, JJ. (2005). "Medias audiovisuels français et langues regionales minorisées. Contexte national et exemples aquitains", Langues d'Aquitaine, dynamiques institutionnelles et patrimoine linguistique, Editions de la Maison des Sciences de l'Homme d'Aquitaine, Bordele.

Duhour, P. (1956, uztailak 12). «Zinema Miresgarria». Herria: journal basquefrançais hebdomadaire.

Etxaluz, K. (2017, abuztuak 25). Elkarrizketa pertsonala.

"Euskara telebixtan". Herria: journal hebdomadaire basque-français,1971-10-17, Baiona.

Ezeiza, A. (1985) Reflexiones para un debate sobre el cine vasco. In Intxausti, J. (zuz). Euskal Herria. Realidad y proyecto. Donostia: Caja Laboral Popular.

Ezkerro, M. (2015, urtarrilak 5). Elkarrizketa pertsonala.

Ferro, M. (1974). Analyse de film, analyse de societes: Une source nouvelle pour l'histoire. Paris: Hachette.

Filma berri bat. (1957, abuztuak 15). Herria: Baiona.

Fuchs, X. (2017, abuztuak 3). Elkarrizketa pertsonala.

Izagirre, K. (1996). Gure zinemaren historia petrala. Donostia: Susa.

Gasteiz, X. (1979): "Baionako irrati telebistak", Jakin, 10. zk (bigarren aldia), 61-64.

Gozillon-Fronsacq, O. (2003) L'Alsace et le Cinema, strategies cinematographiques. Paris: Association Française de recherche sur l'Histoire du Cinema.

Gutierrez, J. (2014, ekainak 3) Elkarrizketa pertsonala.

Guzman, P (2013). Filmar lo que no se ve. Madrid: Docma

Kantero, A. (2017, agorrilak 10). Elkarrizketa pertsonala.

Lahina, E. (1956). «Sor Lekua». Gure herria: bulletin de l'Association «Gure Herria» (XXV), 247-252.

Lopez Echevarrieta, A. (1998). Julian Ajuria: una vida de cine. Bilbao: Bizkaiko Foru Aldundia.

Madré,A (1953, ekainak 13). "Cher monsieur le cure.” Jean Elissalde “Zerbitzari”-ri idatzitako gutuna.

Martinez, J. (2015). Gure zinemaren sor lekua: euskarazko lehen filmaren aurkikunt$z a$, historia eta analisia. Leioa: EHU.

Martinez, J. (2016). Searching for Ramuntcho: foreign filmmakers in the French Basque Country. Communication \& Society 29(3), 16-31.

Mattei, JP. (2008) La Corse, les corses et le cinema. Ajaccio: La cinematheque corse.

Oliarj-Ines, E. (2017, agorrilak 15). Elkarrizketa pertsonala.

Premiere Mondiale du film Sor-lekua entierement en basque (1956, uztailak 7). Basque-Eclair. Baiona. 
Recalt, T. (2017, agorrilak 2). Elkarrizketa pertsonala.

Rekalde, M. (2014, maiatzak 2). Elkarrizketa pertsonala.

Roldán Larreta, C (2003). Los vascos y el séptimo arte. Diccionario enciclopédico de cineastas vascos, Donostia: Euskadiko Filmategia.

Stone, R. \& Rodriguez, M. P. (2015). Basque Cinema. A cultural and political history. London: I.B.Tauris.

Suarez, F (2017, uztailak 5). Elkarrizketa pertsonala.

Torrado, S. (2008). El cine vasco en la bibliografía cinematográfica (1968-2007). Donostia: Universidad de Deusto.

Un film de asuntos vascos será exhibido en el teatro San Martin. (1924, uztailak 31). Nación Vasca: Buenos Aires.

Unsain, J. M. (1985). El cine y los vascos. Donostia: Eusko Ikaskuntza.

Ynchausti, A. (2015, abuztuak 28). Elkarrizketa pertsonala.

Zulaika, J. (1996). Del Cromañon al Carnaval: los vascos como museo antropológico. Donostia: Erein.

Zunzunegui, S. (1985). El cine en el País Vasco. Bilbao: Diputación de Bizkaia. 